\title{
Editorial
}

\section{HR 20/20: Developing future-ready HR Capabilities}

\author{
Sathiyaseelan Balasundaram*
}

\begin{abstract}
The rapid evolution of technology is having a significant impact on work, workplaces and the HR function. The function is under demand to address a range of questions that includes adding strategic value, greater use of technology in HR processes, and making the workforce more agile. In the first part, the paper provides a conceptual overview of the complex forces of change impacting workplaces, work and HR. Next, current literature and industry reports have been reviewed to offer insights on how companies could choose different approaches to respond to these complex forces of change Pathfinding HR, Searching HR, and Disconnected HR. Finally, the paper makes recommendations on the four HR capabilities - workforce shaping, passing the culture test, employee experience by design and workforce insights - companies need to develop to be future-ready.
\end{abstract}

Keywords: Employee Experience, HR 20/20, HR Technology, Workforce shaping, workforce insights

* Institute of Management, CHRIST (Deemed to be University), Bangalore, India; sathiyaseelan.b@christuniversity.in 


\section{Introduction}

This editorial article discusses the changing role of HR resulting from the impact of technology and the global spread of Covid-19 that has changed the very nature of our work and workplaces.

The future is here. When the theme for the HR issue of USHUS was initiated around the early part of the year 2020, the focus was to examine important questions and present actionable insights on the future of work in the context of the rapid evolution of technology and its impact on the role of the HR function. Hence the theme of the issue was set as HR 20/20. But who would have thought the year would bring about such challenges that were never imagined before as a result of the Covid-19 pandemic. Even before Covid-19 became a defining aspect of our personal and professional lives, it was a common refrain that we are living and working in a VUCA world - volatile, uncertain, complex and ambiguous (a term initially coined by the US Army War College). Technology is changing our life and work in ways that we could not have imagined. But Covid-19 has brought in a new dimension to our health, economies, markets and workplaces and its story is still unfolding. A complex, fluid, ever-changing story.

The biggest impact of the combined effect of changing technology and Covid-19 has been on organizations and workplace (Khudhair, Alsaud, Alsharm, Alkaabi, \& AlAdeedi, 2020). As the virus spread across the globe, countries started declaring lockdowns, organizations scrambled to keep their operations running to survive while complying with the lockdown restrictions. The immediate solution to ensuring business continuity was Work From Home (WFH). Before Covid, few companies bothered about WFH policies (Bick, Blandin, \& Mertens, 2020). Those that did have a WFH policy designed it as a flexible benefit offered as a friendly employer. Post-Covid every company rushed to have a policy in place to ensure its survival. Overnight brick and mortar businesses attempted to transform themselves into virtual organizations. And the importance of the human resource (HR) function has become central to business survival.

One thing is clear. HR as a function is experiencing a good amount of adversity as it navigates through today's complex and changing 
world (Holbeche, 2015). In this context, the function is under demand to address a range of questions that include - how can the HR function bring more strategic value to the organization? How can key HR processes that are time-consuming, manpowerintensive, tactical and complex be automated and streamlined? How can the workforce, and more specifically the HR workforce be made agile and equipped to handle new-age technology? How can the right talent be found, retained and motivated? How to drive innovation, efficiency, productivity and stay hyper-competitive? How to align people, processes and systems in a digital and virtual world? How to design an employee experience that responds to the fast-changing and evolving demands? It will be interesting indeed to see later in this article, how different HR groups are addressing these challenges. But before discussing that, it is important to clarify, what exactly are the complex forces of change that HR is confronting today and in the foreseeable future, to which it needs to respond?

Factors that are impacting and continue to impact workplaces and work itself include but are not limited to (a) globalization (and deglobalization), (b) technology, (c) consumerization and (d) multigenerational workforce (Mercer, 2015).

\section{Factors impacting work, workplaces and HR}

Globalization: It is today's reality that there is a flow of products, services, knowledge and talent across countries. Companies are under pressure, on the one hand, to protect and grow in established markets and on the other hand to explore newer market opportunities and develop capabilities to cater to them. This demands that companies build organizational and people agility to operate across different markets and be able to attract, retain and develop top talent (Farndale, Thite, Budhwar, \& Kwon, 2020).

Deglobalization: Multinational corporations construct strategies based on the assumption that the future will bring about more opening of national markets, more international cooperation and easier flow of capital, products, services, knowledge and people across borders. But in recent times it has become amply evident that these assumptions are more not accurate, to say the least, and 
the world is becoming more uncertain, unpredictable and ridden by international conflicts, protectionism and nationalism. These can be considered as a force of deglobalization and demands that companies redevise their strategies based on such factors. HR strategy needs to account for this differential approaches (Farndale et al., 2020).

Technology: The continuing advancement of technology and its application at work is transforming work into a $24 / 7$ reality and blurring the lines between work and personal life. This has fortunate consequences for organizational productivity but can also result in unfortunate consequences for employees physical, emotional and mental wellbeing. Traditional approaches to HR processes will give way to technology-driven systematic and decentralized approaches. The process of identifying talent, matching talent to work and work to talent, and employee development will move online and the HR teams and professionals will need to develop requisite hard and soft skills to stay relevant (Mercer, 2015).

Consumerization: The availability of requisite technologies is empowering customers to shape their own experiences and organizations are under pressure to offer on-demand customized products, services and solutions to consumers. Such changes are visible within organizations as well with the younger workforce 'consumerization' and 'customization' as the guiding principle of the employee-employer relationship. The result of this is the demand by employees for a greater say in shaping the content of their jobs, career goals and even work environment. For organizations, the implication is the need to let go of the 'one size fits all' approach to the design of employee experience and be more responsive to individual needs and demands of employees (Kapoor, 2020).

Multigenerational workforce: Organizations today are seeing four generations in their workforce - boomers (1946 to 1960), Gen X (1961 to 1979), Gen Y (1980 to 1995) (Erickson, 2009) and also the entry of Gen Z (1996 onwards). There is some level of similarity in the working style of each of these generations, but there are also many differences that employers need to pay attention to, such as collaboration style, decisions making, communication, expectations 
regarding rewards, career growth and performance feedback. Organizations feel the pressure to individualize and address the differing needs of these multigenerational workforces (Mercer, 2015).

In a nutshell, complex forces of change that HR is confronting today, include globalization (and deglobalization), technology, consumerization and multigenerational workforce. The question is how exactly can organizations respond to these complex forces of change.

\section{HR response to complex forces of change}

Companies can choose different approaches to respond to these complex forces of changes. We discuss the possible approaches companies could choose from (a) Pathfinding HR (b) Searching HR (c) Disconnected HR (Bolton et al., 2019).

Companies can respond by purposefully building HR capability in all HR domains to shape and prepare the workforce for the future. These can be viewed as organizations that may prefer to adopt a 'Pathfinding $H R^{\prime}$ approach to addressing their $H R$ challenges, meaning they attempt to find their way through business complexity by coursing through unexplored areas. Some organizations could choose to focus on building one or two HR capabilities that they view as important for future survival. This strategy can be viewed as a 'Searching $H R$ ' approach. The challenge for organizations in this approach is to identify one or two HR capabilities that are most relevant to them. A third approach is where HR continues to do what they have been doing in the past as they see it as relevant to their current organizational context. They don't see a need to focus on any specific HR capability to be futureready. These can be classified as 'Disconnected $H R^{\prime}$ (Bolton et al., 2019)approach. The challenge with this approach is, HR may continue to focus on administrative tasks and risk losing relevance or becoming unviable soon.

To recapitulate the discussions so far, the article started with the premise that $\mathrm{HR}$ as a function is experiencing a good amount of adversity as it navigates through today's complex and changing world. It then discussed the complex forces that are redefining the 
HR landscape - globalization (and deglobalization), technology, consumerization and multigenerational workforce. We then saw that companies could address these complex forces of change by taking three distinct approaches - Pathfinding HR, Searching HR and Disconnected HR. We now look at the HR capabilities that companies need to look at addressing to effectively deal with the complex forces of change impacting them.

\section{HR capabilities that companies need to invest in}

KPMG report (Bolton, Holt, \& DiClaudio, 2019) on the future of HR recommends the following four HR capabilities companies need to address to be future-ready (a) workforce shaping (b) passing the culture test (c) redefine employee experience by design (d) workforce insights.

'Workforce shaping'. Adopting a scenario-based approach to defining the workforce required in the next 5-10 years. Understanding the impact that digital disruption will have on organization and workforce. Know the shape, size, composition and skills required to navigate effectively. Foresee how humans and machines will work together to drive organizational performance and value.

What should companies do for 'workforce shaping'? Develop the capability for workforce shaping by investing in roles that are dedicated to business scenario planning based on disruption and productivity potential resulting from technologies like robotic process automation (RPA) and AI, and then work back to offer 'answers' in the present model of working. This requires a different approach than the traditional workforce planning which starts with the existing workforce and moves forward in time. This traditional approach risks missing the enormous disruptive potential and productivity gains that RPA and AI technology could offer. Another focus area is upskilling to meet requirements of the future-state work environment. The upskilling requirement goes in hand in hand with a scalable learning and development initiative. Another point to be considered is, ultimately it is C-suite leadership that owns the outcomes of workforce shaping initiatives. Therefore HR skills should encompass the ability to collaborate with C-suite 
to ensure the success of the workforce shaping effort. Further, regular refreshes of the scenario planning needs to be carried out to understand how the organization could look like and what could be achieved from that.

A quick scenario planning on workforce shaping: Take the case of the healthcare industry. Workers in the healthcare sector may require a different set of skills with redefined roles in the context of technology. For instance, patient consultation and treatment could move to a virtual mode and patient care may be completely redesigned via cognitive AI and robotics augmentation. This will result in demand for new skills such as a community of travelling health care workers who are assisted by cognitive AI and robotics.

'Passing the culture test'. Underlying behaviours and beliefs that define how the work gets done in the organization. Aligning the beliefs and behaviours with the organization's higher-level purpose. Adopting a strategic approach to aligning organizational culture with organizational purpose, that includes mechanisms to monitor and maintain the right culture.

What should companies do to pass the 'culture test'? There is a strong correlation between organizational culture and organizational performance (Aziz, Sumantoro, \& Maria, 2019; GonzálezRodríguez, Martín-Samper, Köseoglu, \& Okumus, 2019; Oyemomi, Liu, Neaga, Chen, \& Nakpodia, 2019; Zhang \& Li, 2016). Despite this strong evidence, for inexplicable reasons, the ownership of the culture agenda is left undecided. Having the right team to drive the culture agenda, establishing dedicated roles for culture change will address the challenge of creating and ensuring alignment across the business. Having such roles will ease the task of understanding current culture, areas that require shift, actions required to attain the desired future state and the business objectives that these will achieve. Those performing these culture roles should be equipped with the systems thinking skill of designing nudging behaviours. The focus of this would be to encourage behaviours that are consistent with achieving organizational objectives, defining who gets rewarded and for what, who becomes the leader, and how employee experiences are to be built that support achievement of organizational goals. In summary, having a dedicated culture role 
can ensure that HR is not always running to catch up with the cultural implications of leadership decisions.

Employee experience by design. Designing an employee experience that mirrors customer experience. Taking a purposeful organization-wide approach to designing employee experiences that are engaging that includes the different types of employee experience: digital experience, that deals with the technology that employees use to accomplish work; social experience, that creates a sense of community and collaboration; environmental experience, that includes the design of the physical workplace. In summary, it means, viewing employee experience from the perspective of the work the employee does, the tools they are provided with to perform the work, and the environment in which they perform the work.

What should companies do for redefining employee experience? Just like seamless customer experience the need for offering seamless employee experience is gaining traction. This demands that HR has the requisite capacity for design thinking and structured problemsolving skills that creates satisfactory employee experiences. This should use advanced approaches for employee experience design that could include employee journey mapping, sentiment analysis of employee social media interactions, wearable devices with monitoring capabilities (Priyadharshini, 2019). The employee experience design must span the whole workforce - direct employees, consultants, contractors and other contingent workers and enhance the positive drivers that motivate employees to engage with the organization.

A quick case scenario on employee experience design: Imagine a manufacturing company that wishes to redesign its HR process to deliver value and offer best-in-class employee experiences to attract and retain high performers, improve customer satisfaction and accelerate growth. One easy way to kick start this process would be to conduct extensive design thinking workshops across the organization, including all HR staff.

Workforce insights. Investing in HR Technology to enhance data analytics capability to support data-based workforce decisions. Using data to address workforce-related business challenges that 
include forestalling involuntary attrition, enhancing productivity, enabling teams to perform at the upper quartile and understanding workforce sentiments. Generating insights on what might happen and actions that are required to address them. Knowing that an out of the box Human Capital Management (HCM) is unlikely to serve the purpose and developing other attributes are needed to turn data insight into action. Protocols around who can access what information.

What should companies do to generate workforce insights? To realize the true value of data analytics organizations need to invest in new technologies but more importantly integrate them with their day to day processes and practices. The investment in technology should extend beyond the traditional out-of-box HCM tools and include functionalities such as data visualization, integration with business metrics such as employee productivity, collaboration and customer experience. The span of technology investment should also include combining data from different sources - HR function, organization-wide data and data from external sources. Based on the data and evidence-based approach should be adopted that subject commonly accepted best practices to rigorous evaluation for validity and relevance. In summary, the focus of technology upgrade should not only be to replace legacy technology and migrate to the cloud, but also to enhance digital service for employees, enhance analytical capabilities, secure privacy of employee data and support employee experience through technology-based service management.

\section{Conclusion}

We are living and working in a VUCA world and the increasingly visible impact of technology in our lives and ways of working in ways that we could not have imagined. Covid-19 brought in a new dimension to this complexity and its story is still unfolding. A story that is complex, fluid, and ever-changing. All these have resulted in a dramatic change in the role of HR in organizations. HR is experiencing a good amount of adversity as it navigates through today's complex and changing world which is shaped by the forces of (a) globalization (and deglobalization), (b) technology, (c) consumerization and (d) multigenerational workforce. The article 
then discussed how companies are addressing these complex forces of change by taking three distinct approaches - (i) Pathfinding HR, (ii) Searching HR and (iii) Disconnected HR. Going further the article offered insights on the four HR capabilities companies need to address to be future-ready (a) workforce shaping (b) passing the culture test (c) redefine employee experience by design (d) workforce insights.

Such being the challenges faced by HR, we now come to some of the other themes on HR that this issue examines and offers actionable insights. These include themes of employee voice and commitment, sustainable HR practices, organizational citizenship behaviours, employee retention, gamification in $\mathrm{HR}$ and the relevance of cultural intelligence. The following paragraphs offer a brief overview of each of the articles included in this issue.

\section{Contents in brief- in the current issue}

The theme of employee voice and commitment is discussed in the paper titled Psychological Safety and Employee Voice in IT Sector: Parallel Mediation Effect of Affective Commitment and Intrinsic Motivation by Jeeva Kuriakose and Devi Soumyaja. Businesses are realizing the positive outcomes of employee wellbeing (Diener \& Seligman, 2004) and research has established that psychological safety is a critical factor in employee wellbeing (Muhammed \& Soumyaja, 2019; Silla \& Gamero, 2018). With this focus in view, this paper studies the relationship between psychological safety on employee voice behaviour by examining the mediating role of affective commitment and intrinsic motivation. The study uses mediation analysis to establish that psychological safety is parallelly mediated by both affective commitment and intrinsic motivation, leading to employee prosocial voice. Also, it offers insight that intrinsic motivation has greater mediating effect than affective commitment.

Increasingly, organizations are promoting Green HR practices to promote employee green behaviour that can contribute to positive environmental outcomes (Dumont, Shen, \& Deng, 2017). But the link between Green HR practices and organizational sustainability have not received much attention. The paper titled Casual Study on Impact of Green HRM Practices on Organisation Sustainability by 
Swarnalatha V addresses this gap. The paper starts with the premise that businesses have changed their view from a traditional financial perspective to competency-based and strategic based perspective. And through extensive literature review, it goes on to discuss the importance of articulating green HR approaches and offers suggestions for businesses to execute green HRM practices that can contribute to enhanced organisational sustainability.

Organizational Citizenship Behaviours (OCBs) have a significant impact on how employees go over and beyond at the workplace and form a competitive edge for their firms (Massoudi, Jameel, \& Ahmad, 2020). Grounded in industrial-organizational psychology, OCBs provide insights for leaders and managers to align and engage staff to improve organizational effectiveness. The paper titled Organizational Citizenship Behaviours - Antecedents, Outcomes $\mathcal{E}$ Paradoxes by Aniisu Verghese takes on this challenging topic. While a lot of studies have focused on the benefits of citizenship behaviours, the paper argues that there are paradoxes which need more attention. And with that perspective in mind, it explores the current literature on $\mathrm{OCB}$, its antecedents, outcomes and paradoxes. Further, it discusses when excessive OCBs can come in the way of organizational success.

A key HR focus for organizations is employee engagement. Gamification is an interesting idea that is gaining traction within $\mathrm{HR}$ as it promises virtual recreation of immersive experiences that can enhance employee engagement and other organizational objectives (Ferrell, Carpenter, Vaughn, Dudley, \& Goodman, 2016). The paper titled Engaging Mind Chemistry with Gamification: HR Practitioners Views by Veena Shenoy takes up this challenge. The study uses a qualitative approach to examine workplace gamification in the $\mathrm{HR}$ process and explores the impact on workplace gamification on employee engagement and experience. Views of HR practitioners from Deloitte, TCS, Wipro, and Continental are taken to understand workplace gamification in the $\mathrm{HR}$ process. It finds that the changing workplace demographics and the entry of tech-savvy and hyperactive millennials are compelling organizations to adopt HR gamification to enhance employee engagement and employee experience. Further, the paper provides insights into the application of gamification in 
various HR processes such as recruitment, training, learning and development, performance management, engagement.

Globalisation has made people increasingly mobile (Collings, 2014). People move across geographies for pursuing education or careers (Baruch, Budhwar, \& Khatri, 2007) and their success in adapting to their new circumstances is often dictated by intercultural skills and capabilities (Doherty, Richardson, Thorn, Al Ariss, \& Crowley-Henry, 2013). The paper titled Cultural Intelligence as a Mediating Factor Among International Students Adaptability in India by Khyati K, Joel Johnson and Vandita Mohta addresses this interesting topic. In this paper, the authors have analysed the problems faced by foreign students in India while adapting to the Indian academic and work environment. The paper is curated in a case study approach through primary research which forms as a base for understanding the situation of foreign students in India and recommending suggestions for reducing cultural conflict. The paper identifies language, cuisine and a limited social circle as the major challenges faced by foreign students. The paper also evaluates the role of cultural intelligence as an enabling factor for better cross-cultural adjustment. Techniques for inculcating cultural intelligence among students is also suggested.

Talent retention is a source of advantage for organizations, but often there are serious challenges that companies encounter in retaining their best (Lin \& Huang, 2020; Mathew \& Manohar, 2016). The paper titled Employee Retention - Challenges and Realities Faced by Corporate For New Recruits As Well As Existing Employees by KM Ravi Kumar Kurumbel takes on this issue. The paper reveals how identifying the employee needs and providing them with the right place in the organization and opportunities to grow can reduce attrition and also provide recruits with better acceptance and support in the organization.

It is my sincere hope that the readers find this issue on HR 20/20 thought-provoking. And hopefully, it offers new insights to scientists, researchers and practitioners to approach HR challenges of the present and future with greater confidence. And it will be rewarding indeed if the ideas expressed in this issue spurs further research in the various HR related to management and business. 


\section{References}

Aziz, A. R. Z., Sumantoro, I. B., \& Maria, D. (2019). Total Quality Management of micro, small and medium enterprises (MSMES), and the impact to organizational culture and performance: emerging country case. Polish Journal of Management Studies, 19.

Baruch, Y., Budhwar, P. S., \& Khatri, N. (2007). Brain drain: Inclination to stay abroad after studies. Journal of World Business, 42(1), 99-112.

Bick, A., Blandin, A., \& Mertens, K. (2020). Work from home after the COVID-19 Outbreak.

Bolton, R., Holt, K., \& DiClaudio, M. (2019). Future of HR 2020: Which path are you taking?

Collings, D. G. (2014). Integrating global mobility and global talent management: Exploring the challenges and strategic opportunities. Journal of World Business, 49(2), 253-261.

Diener, E., \& Seligman, M. (2004). Beyond money: Toward an economy of well-being. Psychological Science in the Public Interest, 5(1), 1-31.

Doherty, N., Richardson, J., Thorn, K., Al Ariss, A., \& Crowley-Henry, M. (2013). Self-initiated expatriation and migration in the management literature. Career Development International.

Dumont, J., Shen, J., \& Deng, X. (2017). Effects of green HRM practices on employee workplace green behaviour: The role of psychological green climate and employee green values. Human Resource Management, 56(4), 613-627.

Erickson, T. (2009). Generational differences between India and the US. Harvard Business Review, 1.

Farndale, E., Thite, M., Budhwar, P., \& Kwon, B. (2020). Deglobalization and talent sourcing: Cross-national evidence from high-tech firms. Human Resource Management.

Ferrell, J. Z., Carpenter, J. E., Vaughn, E. D., Dudley, N. M., \& Goodman, S. A. (2016). Gamification of human resource processes. In Emerging research and trends in gamification (pp. 108-139). IGI Global.

González-Rodríguez, M. R., Martín-Samper, R. C., Köseoglu, M. A., \& Okumus, F. (2019). Hotels' corporate social responsibility practices, organizational culture, firm reputation, and performance. Journal of Sustainable Tourism, 27(3), 398-419.

Holbeche, L. (2015). The Agile Organization: How to build an innovative, sustainable and resilient business. Kogan Page Publishers.

Kapoor, S. (2020). 4 HR Trends in the Era of Artificial Intelligence. In Transforming Management Using Artificial Intelligence Techniques (pp. 51-61). CRC Press.

Khudhair, H. Y., Alsaud, A. B., Alsharm, A., Alkaabi, A., \& AlAdeedi, A. (2020). The Impact of COVID-19 on Supply Chain and Human 
Resource Management Practices and Future Marketing. Int. J Sup. Chain. Mgt Vol, 9(5), 1681.

Lin, C.-Y., \& Huang, C.-K. (2020). Employee turnover intentions and job performance from a planned change: the effects of an organizational learning culture and job satisfaction. International Journal of Manpower.

Massoudi, A. H., Jameel, A. S., \& Ahmad, A. R. (2020). Stimulating organizational citizenship behaviour by applying organizational commitment and satisfaction. International Journal of Social Sciences and Economic Review, 2(2), 20-27.

Mathew, R., \& Manohar, S. J. (2016). Influence of retention strategies on satisfaction level of teachers: A regression model. Ushus Journal of Business Management, 15(3), 33-40.

Mercer. (2015). The Future of HR.

Muhammed, S., \& Soumyaja, D. (2019). Employee Voice and its Relation to the Morale of Employees in the IT Sector in South India. Ushus Journal of Business Management, 18(2), 55-64.

Oyemomi, O., Liu, S., Neaga, I., Chen, H., \& Nakpodia, F. (2019). How cultural impact on knowledge sharing contributes to organizational performance: Using the fsQCA approach. Journal of Business Research, 94, 313-319.

Priyadharshini, S. K. (2019). Redefining Workplace Wellness: Wearable Technology and Corporate Wellness. Ushus Journal of Business Management, 18(2), 43-53.

Silla, I., \& Gamero, N. (2018). Psychological safety climate and professional drivers' well-being: the mediating role of time pressure. Transportation Research Part F: Traffic Psychology and Behaviour, 53, 8492.

Zhang, X., \& Li, B. (2016). Organizational culture and organizational performance: a brief review. Journal of Advances in Social Science and Humanities, 2(05).

\section{Sathiyaseelan B}

Section Editor 